DOI: 10.2478/awutp-2018-0004

Vol. LX, 2018

\title{
MODELING OF DAILY GLOBAL SOLAR IRRADIATION IN TIMISOARA BY USING A FUZZY APPROACH
}

\author{
Remus Boata \\ Romanian Academy Timisoara Branch, Timisoara Astronomical Observatory, A. Sever Sq. 1, 300210 , \\ Timisoara, Romania
}

\begin{tabular}{|l|l|}
\hline \multicolumn{1}{|c|}{ Article Info } & \multicolumn{1}{c|}{ Abstract } \\
\hline Received: 04.06 .2018 & \multicolumn{1}{c|}{ This paper proposes a new simple model to forecast daily global solar } \\
Accepted: 30.07 .2018 & $\begin{array}{l}\text { irradiation one day ahead using the Takagi-Sugeno fuzzy methods. The model is } \\
\text { based on solar radiation data measured in Timisoara, Romania. The daily clearness } \\
\text { index represents the direct variable used by the fuzzy algorithm. The model } \\
\text { forecasts the clearness index at the moment of time } t \text { on basis of two previous } \\
\text { values measured at time } t \text {-1 and } t-2 \text {. An assessment of the model accuracy is } \\
\text { performed. }\end{array}$ \\
$\begin{array}{l}\text { fuzzy systems, solar } \\
\text { irradiation }\end{array}$
\end{tabular}

\section{Introduction}

Models for computing solar radiation represent useful tools in various research areas. Most of these models are based on traditional statistics. Other alternative methods in modeling solar radiation are represented by the fuzzy algorithms [1]. An improvement in the forecasting accuracy is expected from these algorithms. The applications of the fuzzy set theory in solar radiation modeling are reported in many studies ([2], [3] and [4]).

A fuzzy system consists of a map between input and output (antecedent part and consequent part) represented by if - then rules. There are two important classes of fuzzy models, with a different structure of the consequent part. The first class encloses the fuzzy logic models [5], where both parts, the antecedent and the consequent part, are linguistic expressions. The second class includes the Takagi-Sugeno fuzzy models [6], where only the antecedent part is a linguistic expression, while the consequent part is represented by mathematical functions.

In this paper we report a new simple model for forecasting one day ahead daily global solar irradiation, in Timisoara, Romania, by using the Takagi - Sugeno fuzzy technique. The 
direct variable used by the fuzzy algorithm is the clearness index, computed from the measured data of the daily global solar irradiation. Based on the two previous values measured at moments $t-1$ and $t-2$, the model forecasts the clearness index at time $t$.

\section{Database and model description}

The solar irradiance can be characterized by two components, deterministic and stochastic. Seasonal and diurnal variations of solar irradiance represent the deterministic variations. Using the astronomical relationships these variations can be computed. The second component of the solar irradiance, the stochastic variation, can be isolated using the instantaneous clearness index [7]:

$$
k_{t, i}=G / G_{e x t}
$$

In Eq. (1) $G$ represents the horizontal global solar irradiance at ground level and

$$
G_{e x t}=G_{S C} \varepsilon \sin h
$$

is the horizontal extraterrestrial irradiance. $G_{S C}=1366.1 \mathrm{~W} / \mathrm{m}^{2}$ [8] represents the solar constant, $\varepsilon$ is the eccentricity correction factor and $h$ is the sun elevation angle.

The instantaneous clearness index, as defined by Eq. (1), represents a measure of the atmospheric transparency. The clearness index can also be defined for the global solar irradiation, on a given time interval. A review of the statistical behavior of the solar radiation components based on clearness index is described in Ref. [9].

In this work the daily clearness index for global solar irradiation is used, defined as:

$$
k_{t} \equiv H / H_{e x t}
$$

The terms $H$ and $H_{e x t}$ in Eq. (3) represent the daily horizontal global solar irradiation on ground level and the daily solar irradiation at the top of the atmosphere.

The Takagi-Sugeno fuzzy algorithm (TS) was developed by using 1460 data of daily global solar irradiation $\left(H_{t}\right)$ recorded over four years 1998 - 2001 at the station Timisoara (latitude $45^{\circ} 47^{\prime} \mathrm{N}$, longitude $21^{\circ} 17^{\prime} \mathrm{E}$, elevation 90m). World Radiation Data Center, St. Petersburg, Russia [10] represents the source of the measured data. From these data, the 
clearness index $k_{t}$, was calculated using Eq. (3). The first 1095 values measured between 1998 and 2000 have been used to train the model and the data measured from 2001 are used to test the model.

The input variables for TS model, $k_{t-1}$ and $k_{t-2}$, are the clearness index measured at the time $t-1$ and $t-2$, and the output variable, $k_{t}$, is the clearness index forecasted at the moment $t$. Five attributes has assigned for variable $k_{t-1}$ and they are denoted $B 1, B 2, B 3, B 4$ and $B 5$. For variable $k_{t-2}$ only two attributes, $A 1$ and $A 2$, are established.

For the first variable, $k_{t-1}$, the membership functions have been chosen as triangular functions:

$$
\begin{aligned}
& m B 1\left(k_{t-1}\right)= \begin{cases}1 & \text { if } k_{t-1}<c 1 \\
\max \left(0,1-\frac{k_{t-1}-c 1}{b 1-c 1}\right) & \text { otherwise }\end{cases} \\
& m B 2\left(k_{t-1}\right)= \begin{cases}\max \left(0, \frac{k_{t-1}-a 2}{c 2-a 2}\right) & \text { if } k_{t-1}<c 2 \\
\max \left(0,1-\frac{k_{t-1}-c 2}{b 2-c 2}\right) & \text { otherwise }\end{cases} \\
& m B 3\left(k_{t-1}\right)= \begin{cases}\max \left(0, \frac{k_{t-1}-a 3}{c 3-a 3}\right) & \text { if } k_{t-1}<c 3 \\
\max \left(0,1-\frac{k_{t-1}-c 3}{b 3-c 3}\right) & \text { otherwise }\end{cases} \\
& m B 4\left(k_{t-1}\right)= \begin{cases}\max \left(0, \frac{k_{t-1}-a 4}{c 4-a 4}\right) & \text { if } k_{t-1}<c 4 \\
\max \left(0,1-\frac{k_{t-1}-c 4}{b 4-c 4}\right) & \text { otherwise }\end{cases} \\
& m B 5\left(k_{t-1}\right)= \begin{cases}1 \quad \text { if } k_{t-1}>c 5 \\
\max \left(0, \frac{k_{t-1}-a 5}{c 5-a 5}\right)\end{cases}
\end{aligned}
$$

Using our measured data, the determined values of the coefficients from Eq. (4a) to Eq. (4e) are: $c 1=a 2=0.1, a 3=b 1=c 2=0.3, a 4=b 2=c 3=0.5, a 5=b 3=c 4=0.7, b 4$ $=c 5=0.9$. The membership functions of the attributes $B 1, B 2, B 3, B 4$ and $B 5$, are plotted in Figure 1. 


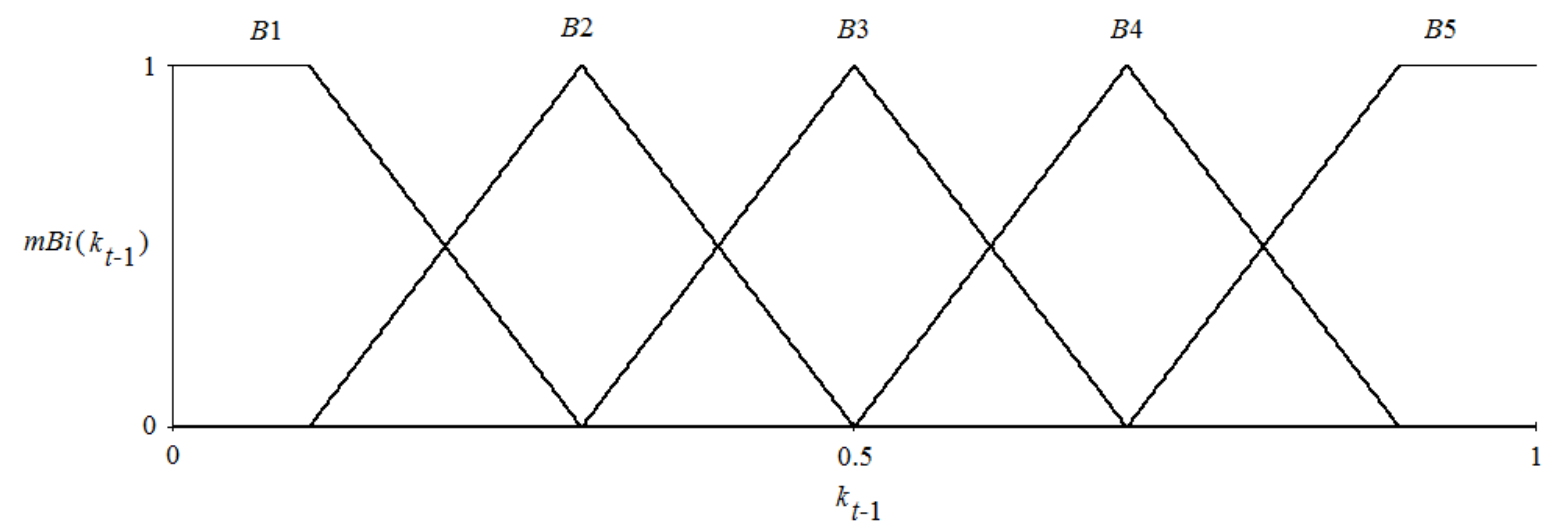

Fig 1. Membership functions associated to the first input variable, $k_{t-1}$.

For the second input variable, $k_{t-2}$, the membership functions have been chosen as trapezoidal functions, illustrated in Figure 2:

$$
\begin{aligned}
& m A 1\left(k_{t-2}\right)= \begin{cases}\max \left(0,1-\frac{k_{t-2}-d_{1}}{e_{1}-d_{1}}\right) & \text { if } d_{1}<k_{t-2} \\
1 & \text { otherwise }\end{cases} \\
& m A 2\left(k_{t-2}\right)= \begin{cases}\max \left(0, \frac{k_{t-2}-d_{2}}{e_{2}-d_{2}}\right) & \text { if } k_{t-2}<e_{2} \\
1 & \text { otherwise }\end{cases}
\end{aligned}
$$

The coefficients of Eq. (5a) and Eq. (5b) are: $d_{1}=d_{2}=0.2, e_{1}=e_{2}=0.6$

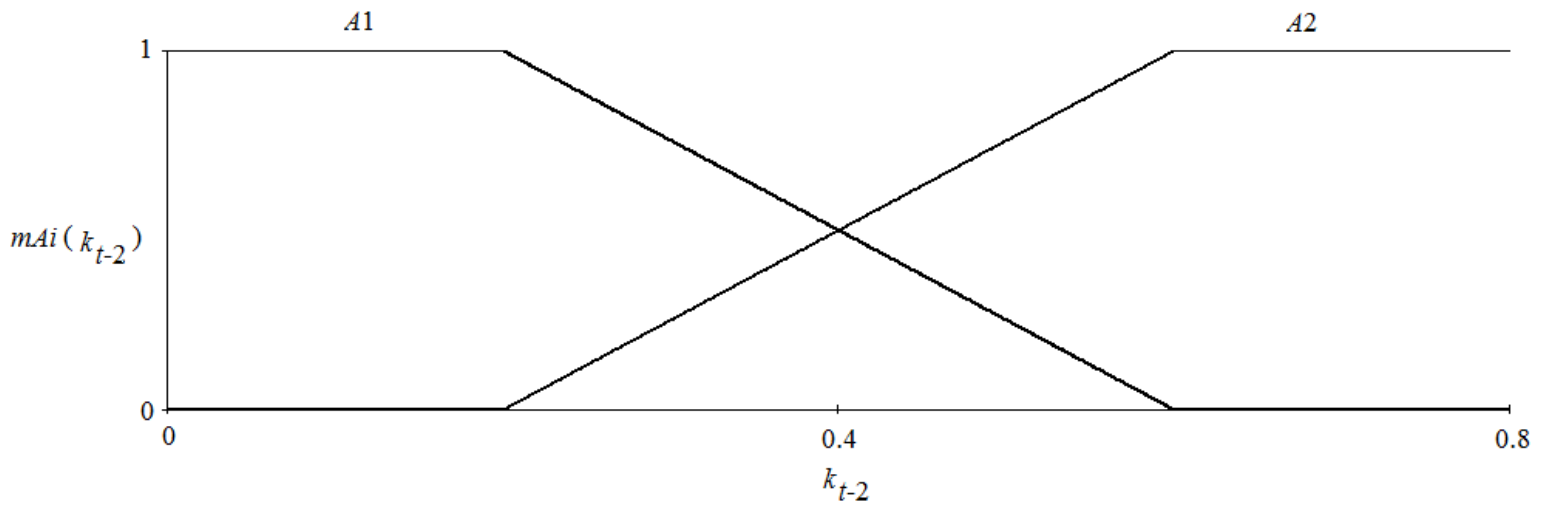

Fig. 2. Membership functions associated to the second input variable, $k_{t-2}$. 
A mapping of the inputs to the output for one fuzzy system is represented by the rules-base [5]. In this paper, the rules-base has been elaborated in a heuristic way using the data from the training period and the TS model contains a set of 10 rules, expressed as:

$$
\# R_{k}: \text { if } k_{t-2} \text { is } A k \text { and if } k_{t-1} \text { is } B k \text { then } f_{k}=f_{k}\left(k_{t-1}, k_{t-2}\right), k=1 . .10 \text {. }
$$

where $A k$ and $B k$ are the fuzzy attributes corresponding to the input variables $k_{t-2}$ and $k_{t-1}$. In Table 1. the structure of the rule-based matrix for our TS fuzzy algorithm is listed.

Table 1. The system rules-base. Each rule is a fuzzy implication in the Eq. (6) sense.

\begin{tabular}{|c|c|c|c|c|c|c|}
\hline \multicolumn{2}{|c|}{ The rules-base } & \multicolumn{5}{c|}{$k_{t-1}$} \\
\cline { 2 - 7 } \multicolumn{2}{|c|}{} & $B 1$ & $B 2$ & $B 3$ & $B 4$ & $B 5$ \\
\hline \multirow{3}{*}{$k_{t-2}$} & $A 1$ & $f_{1}$ & $f_{2}$ & $f_{3}$ & $f_{4}$ & $f_{5}$ \\
\cline { 2 - 7 } & $A 2$ & $f_{6}$ & $f_{7}$ & $f_{8}$ & $f_{9}$ & $f_{10}$ \\
\hline
\end{tabular}

The output functions $f_{i}$ have been chosen linearly in $k_{t-1}$ and $k_{t-2}$ :

$$
f_{i}\left(k_{t-1}, k_{t-2}\right)=\alpha_{i}+\beta_{i} k_{t-1}+\gamma_{i} k_{t-2}, i=1 \ldots 10
$$

The coefficients of the $f_{i}$ output functions have been computed using the multivariate least square regression and they are listed in Table 2.

Table 2. Coefficients in the Eq. (7).

\begin{tabular}{|c|l|l|l|l|l|l|l|l|l|l|}
\hline $\boldsymbol{i}$ & $\mathbf{1}$ & $\mathbf{2}$ & $\mathbf{3}$ & $\mathbf{4}$ & $\mathbf{5}$ & $\mathbf{6}$ & $\mathbf{7}$ & $\mathbf{8}$ & $\mathbf{9}$ & $\mathbf{1 0}$ \\
\hline $\boldsymbol{\alpha}_{\boldsymbol{i}}$ & 0.185 & 0.211 & 0.219 & 0.049 & 1.294 & 0.132 & 0.191 & 0.207 & 0.021 & 0.544 \\
\hline $\boldsymbol{\beta}_{\boldsymbol{i}}$ & 0.108 & 0.116 & 0.129 & 0.137 & 0.129 & 0.228 & 0.179 & 0.086 & 0.014 & -0.001 \\
\hline$\gamma_{i}$ & 0.568 & 0.402 & 0.368 & 0.654 & -1 & 0.591 & 0.378 & 0.432 & 0.807 & 0.122 \\
\hline
\end{tabular}

Once we have set a functional rules-base, the fuzzy algorithm is operational. In this moment, the model can be run and for every inputs $k_{t-1}$ and $k_{t-2}$, the output value $k_{t}$ can be computed. 


\section{Model performance assessment}

To assess the model performance we use data measured in the year 2001 at the station Timisoara. The graphical representation of measured and forecasted values of daily clearness index is illustrated in Figure 3(a). A good agreement between measured and forecasted values of clearness index with the TS fuzzy model can be observed.

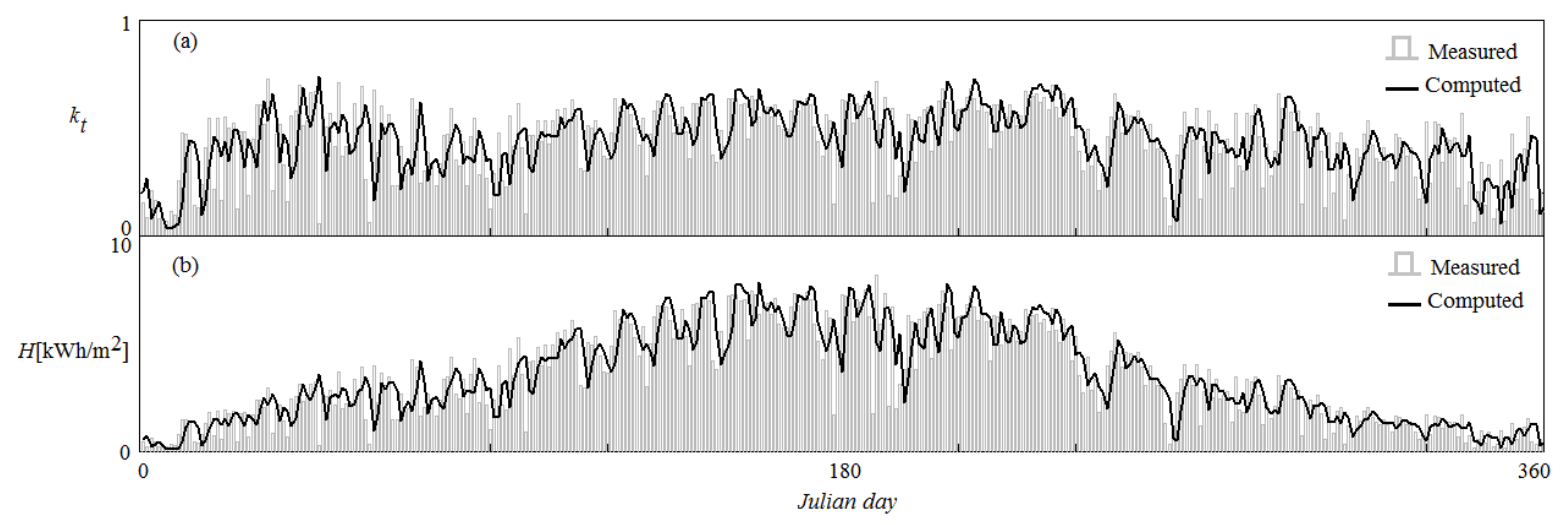

Fig. 3. Comparison between: (a) forecasted and measured daily clearness index; (b) computed and measured daily global solar irradiation. Data recorded in 2001 at station Timisoara are used.

The daily global solar irradiation forecasting is the main scope of this paper. Using Eq. (3), with which we generated the clearness index $k_{t}$, we can reconstruct the data series for daily global solar irradiation. The obtained results are represented graphically in Figure 3(b). In this stage of testing we use data measured at the station Timisoara in the year 2001. The computed values for statistical indicators root mean square error (rmse) and mean bias error (mbe) are: $r m s e=1.178\left[\mathrm{kWh} / \mathrm{m}^{2}\right]$ and $m b e=0.005\left[\mathrm{kWh} / \mathrm{m}^{2}\right]$. Based on the obtained results we can say that the accuracy of forecasting the daily global solar irradiation using the TS fuzzy procedure is acceptable with a good balance between accuracy and simplicity.

\section{Conclusions}

In this paper a new simple model based on the Takagi-Sugeno fuzzy procedure for forecasting daily global solar irradiation one day ahead is presented. The clearness index computed from global solar irradiation is the direct variable processed by the TS fuzzy algorithm. The obtained results in this work show that the accuracy of forecasting using this new procedure is acceptable. The balance between accuracy and simplicity of the TS fuzzy model presented in this work shows that it is suitable for practical applications. By simply recomputing the coefficients, this model can be applied easily in other location. 


\section{References}

[1] L. A. Zadeh. Inf. Control. 8 (1965) 338-353.

[2] A. Mellit. Int. J. Artif. Intell. Soft Comput. vol. 1 (No.1) (2008) 52-76.

[3] R. S. Boata, M. Paulescu. Environmental Engineering and Management Journal 13 (12) (2014) 3045-3051.

[4] R. S. Boata, P. Gravila. Atmospheric Research 112 (2012) 79-88.

[5] H. J. Zimmermann. Fuzzy set theory and its application, Third ed. Kluwer Academic Publishers, Boston (1996).

[6] T. Takagi, M. Sugeno. EEE Trans. Syst. Man Cybern 15 (1985) 116-132.

[7] B. Y. Liu, R. C. Jordan. Solar Energy 4 (1960) 1-19.

[8] C. A. Gueymard. Solar Energy 76 (2004) 423-453.

[9] J. Tovar-Pescador. Modelling the statistical properties of solar radiation and proposal of a technique based on Boltzmann statistics, In: Badescu, V. (Ed.), In Modeling Solar Radiation at the Earth's Surface, Springer, Berlin (2008).

[10] WRDC. World Radiation Data Center, St. Petersburg, Russia, (2018) Available online at: http://wrdc.mgo.rssi.ru/. 